\title{
DIGITIZED RIGHTS AS AN ELECTRONIC AND VIRTUAL FICTION FOR THE LEGAL SUPPORT FOR THE TURNOVER OF SUBJECTIVE CLAIMS
}

\author{
Vitaly A. Sadkov
}

Volgograd Academy of the Ministry of Internal Affairs of the Russian Federation, Volgograd, Russian Federation

Introduction: the paper examines the legal nature of such new categories as "digital rights", "utilitarian digital rights", "digital financial assets" and "digital currency". The correlation of these phenomena with each other is clarified from the standpoint of modern civil turnover. The purpose of the study is to analyze the legally significant features of the above phenomena. Methods: the methodological framework for the study is a set of methods of scientific knowledge, among which the main ones are analysis, synthesis, generalization and comparative law. Results: the author's position justified in the work is based on the legislation and the opinions of the competent scientists on the issues of clarifying the legal essence of the above-mentioned categories from the standpoint of civil law. Conclusions: the author suggests considering "digital rights", "utilitarian digital rights", "digital financial assets" not only from the standpoint of objects of civil rights, but also from the standpoint of the original digital form of fixing property rights. It is proposed to introduce the category "digitized rights" into the legal lexicon as a kind of fiction used to ensure the operability of the legal mechanism that mediates the turnover of subjective claims in the electronic and virtual environment.

Key words: digital rights, digital financial assets, utilitarian digital rights, digital currency, digitized rights.

Citation. Sadkov V.A. Digitized Rights as an Electronic and Virtual Fiction for the Legal Support for the Turnover of Subjective Claims. Legal Concept $=$ Pravovaya paradigma, 2021, vol. 20, no. 2, pp. 159-163. (in Russian). DOI: https://doi.org/10.15688/lc.jvolsu.2021.2.21

УДК 347.22

ББК 67.404 .12
Дата поступления статьи: 02.03.2021

Дата принятия статьи: 29.03.2021

\section{ОЦИФРОВАННЫЕ ПРАВА КАК ЭЛЕКТРОННО-ВИРТУАЛЬНАЯ ФИКЦИЯ ДЛЯ ЮРИДИЧЕСКОГО ОБЕСПЕЧЕНИЯ ОБОРОТА СУБЪЕКТИВНЫХ ТРЕБОВАНИЙ}

\author{
Виталий Андреевич Садков \\ Волгоградская академия Министерства внутренних дел Российской Федерации, \\ г. Волгоград, Российская Федерация
}

\begin{abstract}
Введение: в статье рассматривается правовая природа таких новых категорий, как «цифровые права», «утилитарные цифровые права», «цифровые финансовые активы» и «цифровая валюта». Уточняется соотношение этих явлений с позиций современного гражданского оборота. Целью исследования является проведение анализа юридически значимых признаков вышеуказанных феноменов. Методы: методологическую основу данного исследования составляет совокупность методов научного познания, среди которых основное место занимают анализ, синтез, обобщение и сравнительное правоведение. Результаты: обоснованная ㄱ в работе авторская позиция опирается на законодательство и мнения компетентных ученых по вопросам 을 уточнения правовой сущности вышеназванных категорий с позиций цивилистики. Выводы: автор предлага¿ ет рассматривать «цифровые права», «утилитарные цифровые права», «цифровые финансовые активы» с ๓ позиций не только объектов гражданских прав, но и с позиций оригинальной цифровой формы фиксации 气ै имущественных прав; предлагается ввести в юридический лексикон категорию «оцифрованные права» как త్ (?) щего оборот субъективных требований в электронно-виртуальной среде.
\end{abstract}


Ключевые слова: цифровые права, цифровые финансовые активы, утилитарные цифровые права, цифровая валюта, оцифрованные права.

Цитирование. Садков В. А. Оцифрованные права как электронно-виртуальная фикция для юридического обеспечения оборота субъективных требований // Legal Concept = Правовая парадигма. $-2021 .-$ T. 20, № 2. - C. 159-163. - DOI: https://doi.org/10.15688/lc.jvolsu.2021.2.21

\section{Введение}

Развитие цифровых информационных технологий способствовало появлению нового класса активов, относительно которых между субъектами права стали возникать правовые отношения [8, с. 421]. Для обозначения таких объектов в научной литературе нередко используются такие термины как «криптоактивы» или «виртуальные активы» [1, с. 141].

До марта 2019 г. регулирование общественных отношений, возникающих по поводу криптоактивов осуществлялось исходя из общих принципов права, так как специальные правовые нормы, отражающие специфику гражданского оборота новых явлений, характерных для экосистемы цифровой экономики, отсутствовали. В марте 2019 г. в Гражданский кодекс РФ (далее - ГК РФ) была введена конструкция «цифровые права», а в августе 2019 г. и в июле 2020 г. в соответствии с Федеральным законом «О привлечении инвестиций с использованием инвестиционных платформ и о внесении изменений в отдельные законодательные акты Российской Федерации» от 02.08.2019 № 259-Ф3 (далее - Ф3 № 259 от 2019 г.) и Федеральным законом «О цифровых финансовых активах, цифровой валюте и о внесении изменений в отдельные законодательные акты Российской Федерации» от 31.07.2020 № 259-Ф3 (далее - Ф3 № 259 от 2020 г.) в юридическом лексиконе появились такие выражения, как «утилитарные цифровые права», «цифровые финансовые активы» и «цифровая валюта».

\section{Исследование}

Проблематика определения правовой природы и соотношения категорий «цифровые права», «цифровая валюта», «цифровые финансовые активы», «утилитарные цифровые права» заключается в том, что если опираться на действующие в настоящее время пра- вовые дефиниции этих категорий, содержащиеся в нормах ГК РФ и ФЗ № 259 от 2019 г. и Ф3 № 259 от 2020 г., то цифровой финансовый актив и утилитарное цифровое право есть не что иное, как разновидность категории «цифровое право», рассматриваемой законодателем в качестве специфического объекта гражданских правоотношений.

Согласно п. 1 ст. 141.1 ГК РФ цифровые права представляют собой совокупность обязательственных и иных прав. Если в отношении отнесения к цифровым правам категории «обязательственные права» особых проблем не возникает (главное определиться: кто кредитор, а кто должник), то в отношении допустимости выделения в составе цифровых прав категории «иные права» требуются определенные уточнения.

Помимо обязательственных прав, в цивилистической доктрине в качестве нематериальных объектов гражданских правоотношений выделяются: вещные права; личные неимущественные права; права на результаты интеллектуальной деятельности и корпоративные права. Судя по природе вещных прав, они не могут являться разновидностью цифровых прав, так как объектами вещных прав являются предметы материального мира, а оборот цифровых прав осуществляется в виртуальном пространстве. Не могут относиться к категории цифровых прав и личные неимущественные права, так как они не имеют товарно-стоимостного характера и неотчуждаемы от личности их носителя. Таким образом, российский законодатель под цифровыми правами понимает совокупность обязательственных, корпоративных и исключительных прав.

Нормы ст. 8 ФЗ № 259 от 2019 г. определяют, что разновидностью утилитарных цифровых прав являются: 1) право требовать передачи вещи (вещей), не относящихся к категории «регистрационных вещей», или вещей, сделки с которыми подлежат обязательному 
нотариальному удостоверению; право требовать передачи исключительных прав на результаты интеллектуальной деятельности и (или) прав использования результатов интеллектуальной деятельности; 3) право требовать выполнения работ или оказания услуг. Следует отметить, что содержание и условия осуществления таких прав должны определяться инвестиционной платформой.

В качестве цифровых финансовых активов в соответствии с нормами п. 2 ст. 1 Ф3 № 259 от 2020 г. могут выступать: 1) денежные требования; 2) возможность осуществления прав по эмиссионным ценным бумагам; 3) права участия в капитале непубличного акционерного общества; 4) право требовать передачи эмиссионных ценных бумаг. Эти требования и права считаются цифровыми финансовыми активами только тогда, когда это указано в решении о выпуске цифровых финансовых активов, а учет, обращение и выпуск таких виртуальных активов в информационной системе должны осуществляться с использованием технологии распределенного реестра.

Анализ вышеприведенных правовых конструкций позволяет А.Ю. Чурилову сформулировать обоснованные сомнения в целесообразности позиционирования цифровых прав в качестве специфических объектов гражданских прав. Автор отмечает большую схожесть содержания действующих норм, регламентирующих оборот цифровых прав с нормами, регулирующими оборот бездокументарных ценных бумаг [7, с. 107]. Разделяя данную точку зрения, в процессе исследования современного российского законодательства мы пришли к выводу, что, говоря о категориях «цифровые права», «цифровые финансовые активы» и «утилитарные цифровые права», следует понимать под ними не какие-то особенные объекты гражданских правоотношений, а рассматривать их с позиций формы закрепления совокупности имущественных требований в электронно-виртуальной среде.

Формулируя нормы, касающиеся «утилитарных цифровых прав», законодатель говорит о них, как о способах фиксации имущественных прав, касающихся требований о передаче вещей, об оказании услуг или о выполнении работ, а также о предоставлении исклю- чительных прав на результаты интеллектуальной деятельности, выступающих в качестве эквивалента инвестиционных вложений. Если же законодатель касается общественных отношений по поводу «цифровых финансовых активов», то в данном случае специфика фиксации имущественных прав проявляется в использовании технологии распределенного реестра, а сущностью этих имущественных прав являются требования, имеющие денежно-стоимостное выражение. Думается, что в рамках дискуссии о цифровых финансовых активах вполне обоснованно говорить о них, как о цифровых аналогах векселей, акций, облигаций с денежным покрытием и опционов эмитента.

Что же касается такого феномена, как «цифровая валюта», то это действительно определенное новшество. А.А. Ситник предлагает рассматривать цифровую валюту в качестве «особого финансового инструмента» [5, c. 112].

Согласно п. 3 ст. 1 Ф3 № 259 от 2020 г. цифровой валютой является совокупность электронных данных в форме цифрового кода или обозначения, которые содержатся в информационной системе. Сами по себе эти данные какой-либо ценности не представляют, что позволяет А.О. Иншаковой, А.И. Гончарову, Д.Е. Матыцину и другим ученым обозначать их как «криптозаписи» [3, с. 333, 344; 2, с. 77]. Однако по добровольному соглашению неопределенного круга лиц, являющихся участниками определенной информационной системы, функционирующей по технологии распределенного реестра, эти криптозаписи (как альтернатива существующим фиатным валютам) выступают в этой среде мерилом (эквивалентом) взаимных обязательств и расчетов. Причем этот эквивалент не подвержен администрированию со стороны какого-либо государственного эмиссионного центра, в качестве которого рассматриваются прежде всего национальные финансовые регуляторы (центральные банки) [6, с. 17].

О признании «цифровой валюты» в качестве оригинального объекта гражданских правоотношений, который активно используется в гражданском обороте, свидетельствуют и формулировки Проекта Федерального закона № 1065710-7 «О внесении изменений в части 
первую и вторую Налогового кодекса Российской Федерации» внесенного Правительством Российской Федерации в Государственную Думу РФ [4, с. 5]. В соответствии с п. 3 ст. 1 вышеназванного проекта цифровая валюта рассматривается как имущество, хотя при этом делается оговорка, что такой подход осуществляется в целях налогообложения.

\section{Выводы}

По нашему мнению, нормы, сформулированные в ст. 141.1 ГК РФ, Ф3 № 239 от 2019 г., ФЗ № 239 от 2020 г. должны быть соотнесены с нормами главы 9 ГК РФ, регламентирующей общественные отношения, которые характерны для такого основания возникновения гражданских прав и обязанностей, как «сделка». Мы считаем, что действующая редакция выше обозначенных норм требует достаточно серьезной корректировки, ибо законодателем в данном случае используются конструкции, описывающие оригинальные способы фиксации воли сторон, отражающие взаимосвязь участников гражданского оборота в цифровой среде. Думается, что, характеризуя гражданский оборот в киберпространстве, более корректно употреблять термин «оцифрованные права» нежели «цифровые права». В связи с этим предлагаем в качестве оцифрованных прав рассматривать некую фикцию, используемую для обеспечения работоспособности юридического механизма, опосредующего оборот субъективных имущественных требований в электронно-виртуальной среде.

\section{СПИСОК ЛИТЕРАТУРЫ}

1. Кочергин, Д. А. Экономическая природа и классификация стейблкойнов. Финансы: теория и практика / Д. А. Кочергин // Finance: Theory and Practice. - 2020. - № 24 (6). - C. 140-160. - DOI: https:// doi.org/10.26794/2587-5671-2020-24-6-140-160.

2. Матыцин, Д. Е. Неоиндустриальный инструментарий оборота бездокументарных ценных бумаг: цифровые технологии реализации и защиты прав инвесторов и эмитентов / Д. Е. Матыцин // Legal Concept = Правовая парадигма. - 2020. T. 19, № 3. - C. 73-83. - DOI: https://doi.org/10. 15688/lc.jvolsu.2020.3.10.

3. Объекты гражданских прав : учеб. для бакалавриата, специалитета и магистратуры / под ред.
А. И. Гончарова, А. О. Иншаковой. - 2-е изд. - М. : Юрайт ; Волгоград : Изд-во Волгогр. гос. ун-та, 2019. $-567 \mathrm{c}$.

4. Проект Федерального закона № 1065710-7 «О внесении изменений в части первую и вторую Налогового кодекса Российской Федерации» // Доступ из справ.-правовой системы «КонсультантПлюс».

5. Ситник, А. А. Цифровые валюты: проблемы правового регулирования / А. А. Ситник // Актуальные проблемы российского права. - 2020. T. 15, № 11. - C. 103-113. - DOI: https://doi.org/10. 17803/1994-1471.2020.120.11.103-113.

6. Филиппов, П. М. О феномене «криптовалюта» и допустимости этого термина в современном юридическом лексиконе / П. М. Филиппов, B. А. Садков // Legal Concept $=$ Правовая парадигма. - 2020. - T. 19, № 1. -C. 16-24. - DOI: https://doi. org/10.15688/lc.jvolsu.2020.1.1.

7. Чурилов, А. Ю. К вопросу о целесообразности введения в гражданский кодекс цифровых прав / А. Ю. Чурилов // Legal Concept = Правовая парадигма. - 2020. - Т. 19, № 2. - С. 105-109. - DOI: https://doi.org/10.15688/lc.jvolsu.2020.2.15.

8. Civil Law in the Digital Economy: Analysis of Doctrinal Adaptation Trends / A. O. Inshakova [et al.] // Competitive Russia: Foresight Model of Economic and Legal Development in the Digital Age: Proceedings of the International Scientific Conference in Memory of Oleg Inshakov (1952-2018) / Ed. by A. O. Inshakova, E. I. Inshakova. - Cham : Springer Nature. -2020 . - P. 421-429.

\section{REFERENCES}

1. Kochergin D.A. Ekonomicheskaia priroda i klassifikatsiia steiblkoinov [Economic Nature and Classification of Stablecoins]. Finansy: teoriia $i$ praktika [Finance: Theory and Practice], 2020, no. 24 (6), pp. 140-160. DOI: https://doi.org/10.26794/ 2587-5671-2020-24-6-140-160.

2. Matytsin D.E. Neoindustrialnyi instrumentarii oborota bezdokumentarnykh tsennykh bumag: tsifrovye tekhnologii realizatsii i zashchity prav investorov $\mathrm{i}$ emitentov [The Neoindustrial Tools for the Turnover of Book-Entry Securities: Digital Technologies for Implementing and Protecting the Rights of Investors and Issuers]. Legal Concept, 2020, vol. 19, no. 3, pp. 73-83. (in Russian). DOI: https:// doi.org/10.15688/lc.jvolsu.2020.3.10.

3. Goncharov A.I., Inshakova A.O., eds. Obekty grazhdanskih prav: ucheb. dlja bakalavriata, specialiteta i magistratury [Objects of Civil Rights: Textbook for Bachelor's Degree, Specialization and Master's Degree. Moscow, Jurajt Publ.; Volgograd, Izd-vo Volgogr. gos. un-ta, 2019. 567 p. 
4. Proekt Federalnogo zakona "O vnesenii izmenenii v chasti pervuiu i vtoruiu Nalogovogo kodeksa Rossiiskoi Federatsii” № 1065710-7 [Draft Federal Law "On Amendments to Parts One and Two of the Tax Code of the Russian Federation No. 1065710-7]. Access from Reference Legal System 'KonsultantPlus'.

5. Sitnik A.A. Tsifrovye valyuty: problemy pravovogo regulirovaniya [Digital Currencies: Problems of Legal Regulation]. Aktualnye problemy rossiyskogo prava, 2020, no. 15 (11), pp. 103-113. DOI: https://doi.org/10.17803/1994-1471.2020.120.11.103-113.

6. Filippov P.M., Sadkov V.A. O fenomene «kriptovaliuta» $\mathrm{i}$ dopustimosti etogo termina $\mathrm{V}$ sovremennom iuridicheskom leksikone [On the Phenomenon of "Cryptocurrency" and the Validity of this Term in the Modern Legal Lexicon]. Legal
Concept, 2020, vol. 19, no. 1, pp. 16-23. DOI: https:// doi.org/10.15688/lc.jvolsu.2020.1.2.

7. Churilov A.Yu. K voprosu o tselesoobraznosti vvedeniia v grazhdanskii kodeks tsifrovykh prav [On the Question of Whether Digital Rights Should Be Introduced into the Civil Code]. Legal Concept, 2020, vol. 19, no. 2, pp. 105-109. DOI: https://doi.org/10.15 688/lc.jvolsu.2020.2.15.

8. Inshakova A.O., Inshakova E.I., Ryzhenkov A.J., Sevostyanov M.V. Civil Law in the Digital Economy: Analysis of Doctrinal Adaptation Trends. Competitive Russia: Foresight Model of Economic and Legal Development in the Digital Age: Proceedings of the International Scientific Conference in Memory of Oleg Inshakov (1952-2018). Cham, Springer Nature, 2020, pp. 421-429.

\section{Information About the Author}

Vitaly A. Sadkov, Police Captain, Adjunct of Adjunct Faculty, Volgograd Academy of the Ministry of Internal Affairs of the Russian Federation, Istoricheskaya St, 130, 400089 Volgograd, Russian Federation, wrendek@mail.ru, https://orcid.org/0000-0002-5171-7023

\section{Информация об авторе}

Виталий Андреевич Садков, капитан полиции, адъюнкт адъюнктуры, Волгоградская академия Министерства внутренних дел Российской Федерации, ул. Историческая, 130, 400089 г. Волгоград, Российская Федерация, wrendek@mail.ru, https://orcid.org/0000-0002-5171-7023 